\title{
Compression Specific Toughness of Normal Strength Steel Fiber Reinforced Concrete (NSSFRC) and High Strength Steel Fiber Reinforced Concrete (HSSFRC)
}

\author{
Khaled Marar $^{\mathrm{a} *}, \ddot{O ̈}_{z \text { gür Eren }}{ }^{\mathrm{b}}$ İbrahim Yitmen ${ }^{\mathrm{a}}$ \\ ${ }^{a}$ Department of Civil Engineering, European University of Lefke, \\ Lefke, North Cyprus, Mersin 10, Turkey \\ ${ }^{\mathrm{b}}$ Department of Civil Engineering, Eastern Mediterranean University, \\ Gazimağusa, North Cyprus, Mersin 10, Turkey
}

Received: February 2, 2011; Revised: May 3, 2011

\begin{abstract}
Compression toughness tests were carried out on concrete cylinders reinforced with three different aspect ratios of hooked-end steel fibers 60,75 , and 83 and six different percentages of steel fibers $0.5,1.0,1.25,1.5,1.75$, and $2.0 \%$ by volume of concrete. The w/c ratio used for the normal strength steel fiber reinforced concrete mixes (NSSFRC) was 0.55 , and the water-cementitious ratio $(\mathrm{w} / \mathrm{c}+\mathrm{s})$ for the high strength fiber reinforced concrete mixes (HSSFRC) was 0.31 . For each mix, three test cylinders were tested for compression specific toughness. The effect of fiber reinforcement index: volume of fibers $\times$ length/diameter ratio on compression specific toughness and also on the relationship between these two properties is presented in this paper. As a result, (a) equations are proposed to quantify the effect of fibers on compression toughness ratio of concrete in terms of FRI, (b) equations obtained in terms of FRI and compression specific toughness of plain concrete to estimate both compression specific toughness of NSSFRC and HSSFRC (N.m), (c) equations obtained which represent the relationship between compression toughness index and FRI for NSSFRC and HSSFRC, respectively, and (d) equations obtained to quantify the relationship between compression specific toughness index and fiber reinforcement index for NSSFRC and HSSFRC, respectively. The proposed equations give good correlation with the experimental values.
\end{abstract}

Keywords: high strength concrete, fiber reinforced concrete, compression toughness, stress-strain curves

\section{Introduction}

High strength concrete (HSC) is defined as a concrete having a compressive strength above $55 \mathrm{MPa}$ according to ACI Committee $363^{1}$. The main parameters to produce HSC are low porosity, achieved by using cement content greater than $400 \mathrm{~kg} \cdot \mathrm{m}^{-3}$, well graded aggregates, low w/c ratio, proper compaction and curing, and addition of Superplasticizers to achieve workable concrete mix $^{2}$. High strength concrete is a brittle material and brittleness can be reduced by the addition of short discrete fibers randomly distributed in concrete. The mechanical behavior such as compressive strength, tensile strength, flexural strength, impact strength ${ }^{3-6}$, ductility and flexural toughness of high strength steel fiber reinforced concrete (HSSFRC) is governed by the size, type, fiber volume fraction $\left(V_{f}\right)$, aspect ratio of fibers: $1 / \mathrm{d}$ ratio (length/diameter ratio), and bond between fibers and the cementitious matrix ${ }^{3-5,7}$.

The short discrete fibers delay the propagation of microcracks, due to the fact that, fibers bridge these cracks and restrain their widening, thus improve the post-peak ductility and energy absorption capacity $^{8-10}$. Because of its superior energy absorption capability, fiber reinforced concrete has been widely used in a variety of civil engineering applications such as precast products, shotcrete, offshore structures, seismic structures, pavements, hydraulic structures, repairs, machine foundations, etc.

Incorporation of fibers in concrete leads to a large increase in the compression specific toughness of concrete. Compression specific toughness is measured as the total area under the stress-strain curve; this means that the fibers tend to increase the strain at peak load and provide a great energy absorption in the post-peak region of the stress-strain curve. An absolute measure of toughness is to determine the energy involved in deforming a specimen to some specified deformation, by measuring the area under the stress-strain curve ${ }^{11}$.

A convenient method to quantify the increase in toughness (relative measure) is by using the toughness index. Toughness index is defined as the ratio of the toughness of the fiber reinforced concrete to that of the plain concrete. This approach has been used in compression by Otter and Naaman ${ }^{12}$. Hsu and $\mathrm{Hsu}^{13}$ investigated the stress-strain behavior of HSSFRC under compression. Hookedend steel fibers $(1 / \mathrm{d}=60)$ were used at different volume fractions of $0.5,0.75$, and $1.0 \%$. The compressive strength was in excess of $70 \mathrm{MPa}$. They observed that the post-peak segment of the stress-strain curve is affected by the addition of fibers. An increase in the slope of the descending portion of the curve increased with increasing the fiber volume fraction. The addition of the steel fibers increased the strain corresponding to the peak stress. In their investigation, toughness index is defined as the area under the stress-strain curve of fiber concrete up to a strain of 0.012 , divided by the area under the stress-strain curve of plain concrete up to a strain of 0.012 . Toughness index increased with the increase in the fiber reinforcement index $\left[\mathrm{FRI}=\mathrm{V}_{f}(1 / \mathrm{d})\right]$.

Mohammadi et al. ${ }^{4}$ investigated the properties of SFRC containing fibers of mixed aspect ratio such as compressive strength, splitting tensile strength, flexural strength, and flexural toughness. The sizes of the mixed steel fibers used where $0.6 \times 2.0 \times 25 \mathrm{~mm}$ and $0.6 \times 2.0 \times 50 \mathrm{~mm}$ in different proportions by weight. They reported that the maximum increase in compressive strength of SFRC 
(containing short fibers only) was $25 \%$ over the plain concrete at fiber volume fraction of $2.0 \%$, an increase of $59 \%$ in splitting tensile strength of SFRC with respect to plain concrete (65\% long fibers and $35 \%$ short fibers) at a fiber volume fraction of $2.0 \%$, a maximum increase in flexural strength of SFRC of $100 \%$, and the higher values of the flexural toughness indices were obtained at higher fiber volume fractions and at higher percentages of the longer fibers in SFRC mixes.

An experimental investigation ${ }^{14}$ was carried out on the effect of steel fibers on strain softening of normal, medium, and high strength concretes (35, 50, and $93 \mathrm{MPa}$, respectively). Hooked-end steel fibers with $1 / \mathrm{d}$ ratio of 75 and $100\left(60 / 0.8\right.$ and $\left.50 / 0.5 \mathrm{~mm} . \mathrm{mm}^{-1}\right)$ were used. The dosages of the first type were 40 and $60 \mathrm{~kg} \cdot \mathrm{m}^{-3}$ and for the second type was $40 \mathrm{~kg} \cdot \mathrm{m}^{-3}$. It was observed that as the strength increased, the descending branch of the stress-strain curve became steeper. The toughness for the normal strength, medium strength, and HSSFRC, was computed up to a strain of 0.007 . For the HSC specimens, the area under the stress-strain curves was determined up to a strain of 0.003. The overall mean specific toughness (toughness/strength) for the HSSFRC was 3.40, which was the same as for the normal strength concrete. Compared with the plain high strength concrete (HSC), giving specific toughness of 1.62, the specific toughness had more than doubled.

In an investigation ${ }^{15}$ on the optimum use of pozzolanic materials such as pulverized fuel ash (PFA) and condensed silica fume (CSF) in steel fiber reinforced concrete, it was concluded that an increase in PFA-binder ratio up to $20 \%$ improved the compressive strength (from 40 to $43 \mathrm{MPa}$ ) and compression energy absorption capacity (from 289565 to $489503 \mathrm{~N} . \mathrm{m} . \mathrm{m}^{-3}$ ) of the high strength fiber reinforced concrete and the increase in CSF-binder ratio up to $10 \%$ improved the compressive strength (from 42 to $56 \mathrm{MPa}$ ) and energy absorption capacity (from 26882 to 565341 N.m.m ${ }^{-3}$ ). The compressive energy absorption used in their investigation is defined as the area under the compressive stress-strain curve up to a strain 5.5 times the strain at peak compressive stress.

In a research ${ }^{16}$ on the stress-strain relationship of HSSFRC in compression, the steel fibers used were hooked-end with $1 / \mathrm{d}$ ratio of $60\left(30 / 0.5 \mathrm{~mm} \cdot \mathrm{mm}^{-1}\right)$, and compressive strength ranged from 70.2 to $113.1 \mathrm{MPa}$. The toughness index used is defined as the ratio of the area under the stress-strain curve up to a strain of $3 \varepsilon_{0}$ to the area up to a strain of $\varepsilon_{0}$ (strain at peak stress). In another investigation ${ }^{17}$, the toughness index was defined as the area under the stress-strain curve of fiber reinforced concrete up to a strain of 0.006 divided by the area under the stress-strain curve of plain concrete up to a strain of 0.006 .

Bhargava et al. ${ }^{18}$ investigated the compressive stress-strain curve of small scale steel fiber reinforced high strength concrete cylinders $(100 \times 200 \mathrm{~mm})$. The experimental variables were concrete strength of 58.03 and $76.80 \mathrm{MPa}$, fiber volume fractions $0.5,1.0,1.5$, and $2.0 \%$, and fiber $1 / \mathrm{d}$ ratio of 20 and 40 of flat crimped steel fibers. The toughness ratio studied was at a strain of 0.015 . They concluded that a) high strength concrete can be made to behave in a ductile manner by the incorporating a suitable fibers, b) short fibers were more effective in controlling early cracking hence enhancing the strength of the composite, c) long fibers were more effective in providing post-peak toughness, d) the gain in the peak stress over plain concrete increased with increase in the fiber volume fraction at a constant $1 / \mathrm{d}$ ratio, e) and when short and long fibers were blended together at an optimum mix proportions, the strength of the composite and postpeak toughness of fibrous concrete can be achieved compared to the mix with a single fiber type.

The stress-strain relationship of the material is an important criterion for proper design, and some design codes for reinforced concrete structures are based on the ultimate strength and uses portion of the strain softening branch of concrete in compression.
Only few researches exist in the literature on compression specific toughness of NSSFRC and HSSFRC. The short comings of the previous researches on compression toughness of concrete can be summarized as follows: a) researches done only on one single fiber $1 / \mathrm{d}$ ratio, b) no relationships between compression toughness and FRI were obtained that count different $1 / \mathrm{d}$ ratios in the relationships, c) studies were limited for fiber volume fractions to less than $2.0 \%$, d) studies on compression toughness were computed for strains less than 0.0333 . The main objectives of this study described in this paper is to produce relationships in terms of compression toughness of plain concrete and fiber reinforcement index for normal and high strength steel fiber reinforced concretes which counts for different 1/d ratios hence different FRI's, also for a more detailed fiber volume fractions, and computations of compression toughness up to a strain of 0.0333 , so that from these simple relationships we can calculate the compression specific toughness of NSSFRC and HSSFRC.

\section{Experimental Program}

\subsection{Concrete}

The w/c ratio used for the normal strength steel fiber reinforced concrete mixes (NSSFRC) was 0.55 , and the water-cementitious (cement and silica fume) ratio (w/c+s) used for the high strength fiber reinforced concrete mixes (HSSFRC) was 0.31. Blast-furnace slag cement complying with ASTM C 595-9719 was used for NSSFRC and HSSFRC mixes. The silica fume was used as an addition to the blast-furnace slag cement at $10 \%$ by weight of the cement for only the HSSFRC mixes. The dosage of the high-range water reducing admixture (HRWRA) used was 1.3 and $3.0 \%$ for the NSSFRC and HSSFRC mixes by weight of the cement, respectively. The maximum size of coarse aggregate used was $20 \mathrm{~mm}$ for all mixes. All the aggregates used were crushed limestone and their gradings complied with ASTM C 33-9320. The specific gravities of of the fine and coarse aggregates used were 2.69 and 2.70 , respectively. The fineness modulus of fine aggregate was 2.83 . The mix proportioning for NSSFRC and HSSFRC are shown in Table 1.

\subsection{Steel fibers}

Hooked-end bundled steel fibers with three different 1/d ratios of 60,75 , and 83 were used in this investigation. The lengths and diameters of the three types of fibers were $30,60,50 \mathrm{~mm}$ and $0.50,0.80,0.60 \mathrm{~mm}$, respectively. Six different fiber volumes were added to each of NSSFRC and HSSFRC mixes at 0.5, 1.0, 1.25, $1.50,1.75$, and $2.0 \%$ by volume of concrete (i.e. $39.25,78.50,98.13$, $117.75,137.38$, and $\left.157.00 \mathrm{~kg} \cdot \mathrm{m}^{-3}\right)$.

\subsection{Experiments on fresh concrete}

The workability of freshly mixed concrete was measured by using VeBe consistometer according to BS 1881: Part 104: $1983^{21}$.

Table 1. Mix proportioning for NSSFRC and HSSFRC mixes.

\begin{tabular}{lcc}
\hline Ingredient & $\begin{array}{c}\text { NSSFRC } \\
\left(\mathrm{kg} \cdot \mathrm{m}^{-3}\right)\end{array}$ & $\begin{array}{c}\text { HSSFRC } \\
\left(\mathrm{kg} \cdot \mathrm{m}^{-3}\right)\end{array}$ \\
\hline Cement & 410 & 565 \\
Water & 225 & 191 \\
HRWRA & 5 & 17.0 \\
Silica fume & - & 56.5 \\
Coarse aggregate & 829 & 1150 \\
Fine aggregate & 916 & 530 \\
\hline
\end{tabular}


Air content of freshly mixed concrete was measured by using the pressure method in accordance with ASTM C 231-91 $\mathrm{b}^{20}$. The concrete cylindrical specimens were prepared and cured according to BS 1881: Part 111: $1983^{22}$, and all the specimens were compacted in cylindrical steel moulds by means of laboratory vibrating table.

\subsection{Compressive strength and compression specific toughness tests}

The size of standard cylinder mould used for compressive strength of NSSFRC and HSSFRC was $150 \times 300 \mathrm{~mm}$. For each mix (total of 38 mixes), three test cylinders were casted. For compressive strength tests, the cylindrical test specimens were capped at both ends with a capping compound in accordance with ASTM C 617-9420. All test specimens were tested for 28 days after casting to obtain an average value for each test. The tests were conducted in a digital closed-loop servo controlled compression testing machine with a capacity of $3000 \mathrm{KN}$.

The stress-strain curves were obtained by using two linear variable differential transformers (LVDT) that were placed at an angle of $180^{\circ}$ around the test specimens to measure the axial platen-to-platen deformations. A personal computer served as a data acquisition system was used to record the data. The loading rate adapted throughout this investigation was $0.03 \mathrm{~mm} / \mathrm{min}$. In an investigation ${ }^{23}$, a comparison between platen-to-platen axial deformation measurements (gauge length of $200 \mathrm{~mm}$ ) and mid span deformation measurements by using extensometer attached to the midsection of the specimen (gauge length of $100 \mathrm{~mm}$ ) had been made. It was observed that the extensometer gauge reading was disturbed by the cracks formed on the specimen surface, and it was concluded that the extensometer gauge reading might not be useful in the study of the strain softening behavior of concrete. Therefore, in this investigation, axial platen-toplaten deformation measurements were chosen.

The compression specific toughness energy $\left(C T_{c f}\right)$ absorption (N.m) was calculated as the area under the load-deformation curve at a maximum deflection of ultimate strain of $0.0333 \mathrm{~mm} \cdot \mathrm{mm}^{-1}$ for all the cylindrical test specimens. In order to calculate the area under the load-deformation curve exactly, a computer program was written in Fortran Language based on Trapezoidal Rule. The developed program can read the data file up to the required deformation.

\section{Experimental Results}

VeBe time test results are shown in Table 2. It can be seen from Table 2 that as the fiber volume fraction increases the VeBe time also increases for both NSSFRC and HSSFRC. The highest VeBe time result of 153.4 seconds is obtained for the NSSFRC mix with $1 / \mathrm{d}$ ratio of 75 and fiber volume fraction of $2.0 \%$, followed by the results of 113.3 seconds for the NSSFRC mix with $1 / \mathrm{d}$ ratio of 83 , followed by the results of 33.9 seconds for the NSSFRC mix with $1 / \mathrm{d}$ ratio of 60 at fiber volume fraction of $2.0 \%$. The highest VeBe time test result ( 162.16 seconds) is obtained for the HSSFRC mix with $1 / \mathrm{d}$ ratio of 75 , followed by the mix with $1 /$ d ratio of 83 ( 95.61 seconds), followed by the mix with $1 / \mathrm{d}$ ratio of 60 (28.42 seconds) at fiber volume fraction of $2.0 \%$. Consequently, consistency decreases with increasing fiber volume fraction.

Air content test results for the NSSFRC and HSSFRC mixes are as given in Table 2. As it can be seen from Table 2, there is no very clear relationship between fiber volume fraction and air content. The fresh NSSFRC with 1/d ratio of 60 and at all fiber volume fractions have higher air contents than the other two fresh NSSFRC mixes with $1 / \mathrm{d}$ ratio of 75 and 83 . At fiber volume fraction of $2.0 \%$, the highest air content is obtained for the fresh NSSFRC mix with $1 / \mathrm{d}$ ratio of $60(1.6 \%)$ followed by the fresh NSSFRC mix with $1 / \mathrm{d}$ ratio of $75(0.5 \%)$ followed by the fresh NSSFRC mix with $1 / \mathrm{d}$ ratio of $83(0.4 \%)$. At $1 / \mathrm{d}$ ratio of 60,75 , and 83 , as the fiber volume fraction increases the air content percentage decreases for all of the fresh HSSFRC mixes. The highest air content test results is obtained for $1 / \mathrm{d}$ ratio of 60 at any fiber volume percentage, followed by $1 / \mathrm{d}$ ratio of 75 , followed by $1 / \mathrm{d}$ ratio of 83 . The highest increase in air content $(1.05 \%)$ is obtained from the fresh HSSFRC mix with $1 / \mathrm{d}$ ratio of 60 and at a fiber volume fraction of $0.5 \%$. The lowest air content test result $(0.39 \%)$ is obtained from the fresh HSSFRC mix with $1 / \mathrm{d}$ ratio of 83 at a fiber volume fraction of $2.0 \%$.

In order to quantify the effect of steel fiber addition on the descending portion of the stress-strain curve of NSSFRC and HSSFRC, compression specific toughness criterion is used, defined as the area under the complete stress-strain curve. Compression specific toughness test results of NSSFRC are given in Table 2. The stress-strain curves of NSSFRC for $1 / \mathrm{d}$ ratio of 60,75 , and 83 at fiber volume fraction of $0.0,0.5,1.0,1.25,1.50,1.75$, and $2.0 \%$ are shown in Figures 1, 2, and 3, respectively. Figure 4 shows compression specific toughness of NSSFRC versus fiber volume fraction. As it can be seen from Figure 4, as the fiber volume fraction increases, compression specific toughness increases for all NSSFRC mixes. The maximum increase in compression specific toughness is 5.68 times compression specific toughness of plain normal strength concrete obtained by the NSSFRC mix with 1/d ratio of 83 and at fiber volume fraction of $2.0 \%$. For NSSFRC mixes with $1 / \mathrm{d}$ ratio of 60 and 75 , the maximum increase in compression specific toughness is 4.43 and 5.36 times compression specific toughness of plain normal strength concrete, respectively, obtained at fiber volume fraction of $2.0 \%$.

The stress-strain curves of HSSFRC for $1 / \mathrm{d}$ ratio of 60,75 , and 83 at fiber volume fraction of $0.0,0.5,1.0,1.25,1.50,1.75$, and $2.0 \%$ are shown in Figures 5, 6, and 7, respectively. Figure 8 shows the compression specific toughness of HSSFRC versus fiber volume fraction. As it can be seen from Figure 8, as the fiber volume fraction increases, compression specific toughness increases for all HSSFRC mixes. The maximum increase in compression specific toughness is 8.38 times compression specific toughness of plain HSC obtained by the HSSFRC mix with $1 / \mathrm{d}$ ratio of 83 and fiber volume fraction of $2.0 \%$. For HSSFRC mixes with $1 / \mathrm{d}$ ratio of 60 and 75 , the maximum increase in compression specific toughness is 6.33 and 7.56 times compression specific toughness of plain HSC, respectively, obtained at fiber volume fraction of $2.0 \%$.

Figure 9 shows the relationship between compression specific toughness $\left(C T_{c f}\right)$ and FRI for both NSSFRC and HSSFRC. From Figure 9, it can be seen that as the FRI increases, compression specific toughness increases for both NSSFRC and HSSFRC. From regression analysis, the following non-linear Equations 1 and 2 are obtained for NSSFRC and HSSFRC (N.m), respectively. Equations 1 and 2 give compression specific toughness of NSSFRC $\left(C T_{n c}\right)$ and HSSFRC $\left(C T_{h c f}\right)$, respectively, in function of FRI and the compression specific toughness of plain concrete $\left(C T_{c}\right) \cdot \mathrm{R}_{\text {CMD }}^{2}$ for Equations 1 and 2 are 0.97223 and 0.97405 , respectively. Therefore, compression specific toughness $\left(C T_{c f}\right)$ of NSSFRC and HSSFRC can be estimated from Equations 1 and 2 in terms of compression specific toughness of plain concrete $\left(C T_{c}\right)$ and fiber reinforcement index, respectively.

$$
C T_{n c f}=C T_{c}+18.59238 V_{f}(l / d)+0.06027\left[V_{f}(l / d)\right]^{2}
$$

for $0 \leq \mathrm{V}_{\mathrm{f}}(\mathrm{l} / \mathrm{d}) \leq 166$

$$
C T_{h c f}=C T_{c}+41.65914 V_{f}(l / d)+0.05078\left[V_{f}(l / d)\right]^{2}
$$

for $0 \leq \mathrm{V}_{\mathrm{f}}(1 / \mathrm{d}) \leq 166$

where $C T_{n c f}, C T_{h c c}$, and $C T_{c}$ are compression toughness energies (N.m) of NSSFRC, HSSFRC, and plain concrete, respectively. 
Table 2. Air content, VeBe time, compressive strength at 28 days, compression specific toughness $\left(\mathrm{CT}_{\mathrm{cf}}\right)$, compression toughness index $\left(\mathrm{T}_{\mathrm{If}}\right)$, and compression specific toughness index $\left(\mathrm{T}_{\mathrm{sf}}\right)$ test results of NSSFRC and HSSFRC.

\begin{tabular}{|c|c|c|c|c|c|c|c|c|c|c|}
\hline Concrete & $1 / \mathrm{d}$ ratio & $\begin{array}{c}\text { Fiber volume } \\
\text { fraction, } \\
\mathrm{V}_{\mathrm{f}}(\%) \\
\end{array}$ & $\begin{array}{c}\text { FRI } \\
\mathrm{V}_{\mathrm{f}}(\mathrm{l} / \mathrm{d})\end{array}$ & $\begin{array}{c}\text { Air } \\
\text { content }(\%)\end{array}$ & $\begin{array}{l}\text { VeBeTime } \\
\text { (seconds) }\end{array}$ & $\begin{array}{l}\text { Compressive } \\
\text { strength, } \mathrm{f}_{\mathrm{c}}^{\prime} \\
(\mathrm{MPa})\end{array}$ & $\begin{array}{l}\mathrm{CT}_{\mathrm{cf}} \\
(\mathrm{N} . \mathrm{m})\end{array}$ & $\begin{array}{l}{ }^{*} \text { Increase } \\
\text { in } \mathrm{CT}_{\mathrm{cf}}(\%)\end{array}$ & $\mathrm{T}_{\text {If }}$ & $\begin{array}{c}\mathrm{T}_{\mathrm{sf}} \\
\left(10^{-3}\right)\end{array}$ \\
\hline \multirow{19}{*}{ NSSFRC } & - & 0.0 & 0.0 & 1.75 & 1.38 & 32.06 & 947.90 & - & 1 & 5.577 \\
\hline & 60 & 0.5 & 30 & 2.00 & 1.35 & 32.66 & 1679.71 & 77.203 & 1.772 & 9.701 \\
\hline & 60 & 1.0 & 60 & 1.90 & 2.10 & 34.11 & 2306.62 & 143.340 & 2.433 & 12.756 \\
\hline & 60 & 1.25 & 75 & 1.95 & 1.81 & 36.28 & 2690.13 & 183.799 & 2.838 & 13.988 \\
\hline & 60 & 1.5 & 90 & 1.80 & 17.31 & 37.46 & 3275.44 & 245.547 & 3.455 & 16.492 \\
\hline & 60 & 1.75 & 105 & 1.80 & 26.72 & 39.27 & 3637.41 & 283.734 & 3.837 & 17.472 \\
\hline & 60 & 2.0 & 120 & 1.60 & 33.92 & 39.85 & 4200.58 & 343.146 & 4.431 & 19.885 \\
\hline & 75 & 0.5 & 37.5 & 1.10 & 1.20 & 33.73 & 1795.59 & 89.428 & 1.894 & 10.042 \\
\hline & 75 & 1.0 & 75 & 1.15 & 1.00 & 34.63 & 2376.62 & 150.725 & 2.433 & 12.947 \\
\hline & 75 & 1.25 & 93.75 & 1.85 & 1.50 & 36.61 & 2931.57 & 209.270 & 3.093 & 15.105 \\
\hline & 75 & 1.5 & 112.5 & 0.70 & 31.94 & 38.31 & 3541.46 & 273.611 & 3.736 & 17.435 \\
\hline & 75 & 1.75 & 131.25 & 0.65 & 90.47 & 39.63 & 4729.77 & 398.974 & 4.990 & 22.510 \\
\hline & 75 & 2.0 & 150 & 0.50 & 113.38 & 41.17 & 5085.26 & 436.476 & 5.365 & 23.300 \\
\hline & 83 & 0.5 & 41.5 & 0.95 & 1.66 & 33.99 & 2058.30 & 117.143 & 2.171 & 11.424 \\
\hline & 83 & 1.0 & 83 & 1.00 & 4.79 & 35.26 & 2518.28 & 165.669 & 2.657 & 13.473 \\
\hline & 83 & 1.25 & 103.75 & 0.95 & 15.84 & 37.09 & 3541.91 & 273.659 & 3.737 & 18.015 \\
\hline & 83 & 1.5 & 124.5 & 0.85 & 97.15 & 39.73 & 4505.81 & 375.347 & 4.753 & 21.390 \\
\hline & 83 & 1.75 & 145.25 & 0.90 & 105.45 & 41.27 & 5090.90 & 437.071 & 5.371 & 23.268 \\
\hline & 83 & 2.0 & 166 & 0.40 & 153.46 & 42.87 & 5386.12 & 468.216 & 5.682 & 23.701 \\
\hline \multirow{19}{*}{ HSSFRC } & - & 0.0 & 0.0 & 1.20 & 3.52 & 73.50 & 1123.70 & - & 1 & 2.884 \\
\hline & 60 & 0.5 & 30 & 1.05 & 5.60 & 76.02 & 2498.83 & 122.375 & 2.224 & 6.200 \\
\hline & 60 & 1.0 & 60 & 0.95 & 10.91 & 78.48 & 3230.14 & 187.456 & 2.875 & 7.764 \\
\hline & 60 & 1.25 & 75 & 0.45 & 13.45 & 80.09 & 4186.41 & 272.556 & 3.726 & 9.860 \\
\hline & 60 & 1.5 & 90 & 0.80 & 17.28 & 84.63 & 5101.76 & 354.014 & 4.540 & 11.372 \\
\hline & 60 & 1.75 & 105 & 0.40 & 21.35 & 86.22 & 5740.61 & 410.867 & 5.109 & 12.559 \\
\hline & 60 & 2.0 & 120 & 0.70 & 28.42 & 88.97 & 7111.25 & 532.842 & 6.328 & 15.077 \\
\hline & 75 & 0.5 & 37.5 & 0.85 & 8.77 & 76.96 & 3144.95 & 179.875 & 2.799 & 7.708 \\
\hline & 75 & 1.0 & 75 & 0.75 & 22.31 & 78.85 & 4329.62 & 285.300 & 3.853 & 10.358 \\
\hline & 75 & 1.25 & 93.75 & 0.40 & 28.51 & 84.48 & 5451.77 & 385.162 & 4.852 & 12.172 \\
\hline & 75 & 1.5 & 112.5 & 0.80 & 40.74 & 87.40 & 6033.96 & 436.973 & 5.370 & 13.021 \\
\hline & 75 & 1.75 & 131.25 & 0.45 & 83.22 & 89.52 & 7374.63 & 556.281 & 6.563 & 15.539 \\
\hline & 75 & 2.0 & 150 & 0.75 & 95.61 & 91.49 & 8493.08 & 655.814 & 7.558 & 17.511 \\
\hline & 83 & 0.5 & 41.5 & 0.95 & 11.82 & 78.02 & 3944.13 & 250.995 & 3.510 & 9.535 \\
\hline & 83 & 1.0 & 83 & 0.90 & 30.41 & 80.95 & 5120.59 & 355.690 & 4.556915 & 11.932 \\
\hline & 83 & 1.25 & 103.75 & 0.45 & 45.36 & 86.21 & 6213.49 & 452.949 & 5.529 & 13.595 \\
\hline & 83 & 1.5 & 124.5 & 0.80 & 98.72 & 89.19 & 7471.04 & 564.861 & 6.649 & 15.801 \\
\hline & 83 & 1.75 & 145.25 & 0.40 & 125.68 & 91.73 & 8378.16 & 645.587 & 7.456 & 17.229 \\
\hline & 83 & 2.0 & 166 & 0.75 & 162.16 & 93.56 & 9417.60 & 738.089 & 8.381 & 18.986 \\
\hline
\end{tabular}

* Increase in compression specific toughness with respect to compression specific toughness of plain concrete.

Compression toughness index $\left(T_{I f}\right)$ is calculated from Equation 3. Compression toughness index is defined as the ratio of the compression specific toughness of the fiber reinforced matrix to that of the plain matrix. Compression toughness indices for NSSFRC and HSSFRC are given in Table 2. The relationship between compression toughness index and FRI is given in Figure 10 for both NSSFRC and HSSFRC. As can be seen form Figure 10, as fiber reinforcement index increases, compression toughness index also increases for both NSSFRC and HSSFRC. As a result of regression analysis, the linear
Equations 4 and 5 were obtained which represent the relationship between compression toughness index and FRI for NSSFRC and HSSFRC, respectively. $\mathrm{R}_{\text {CMD }}$ for Equations 4 and 5 is 0.95818 and 0.96947 , respectively.

$$
T_{i f}=\frac{C T_{c f}}{C T_{c}}
$$

for $947.9 \leq \mathrm{CT}_{\mathrm{cf}} \leq 9417.6$ N.m 


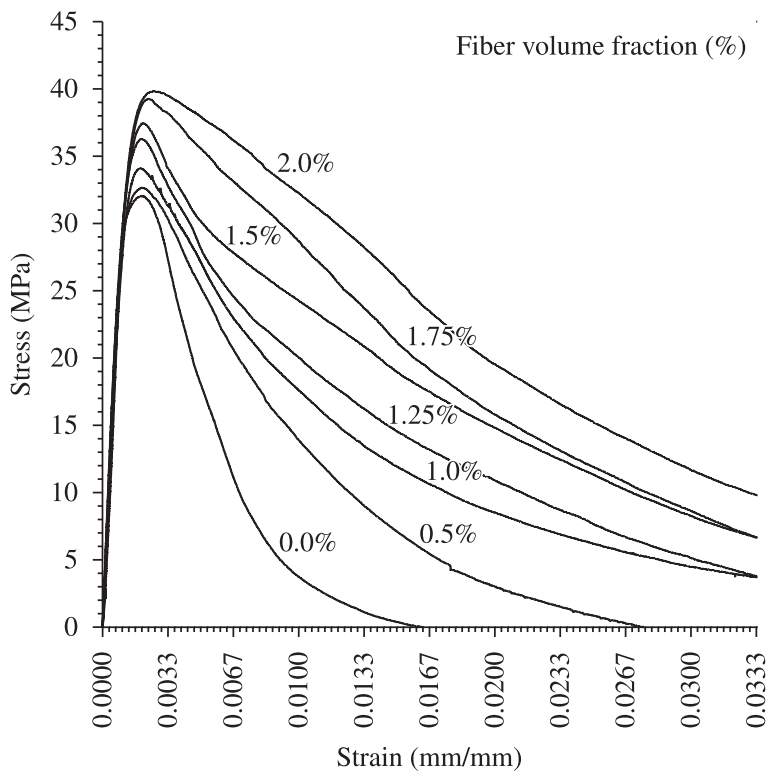

Figure 1. Stress-strain curves of NSSFRC for $1 / \mathrm{d}$ ratio of 60 at fiber volume fraction of $0.0,0.5,1.0,1.25,1.5,1.75$, and $2.0 \%$.

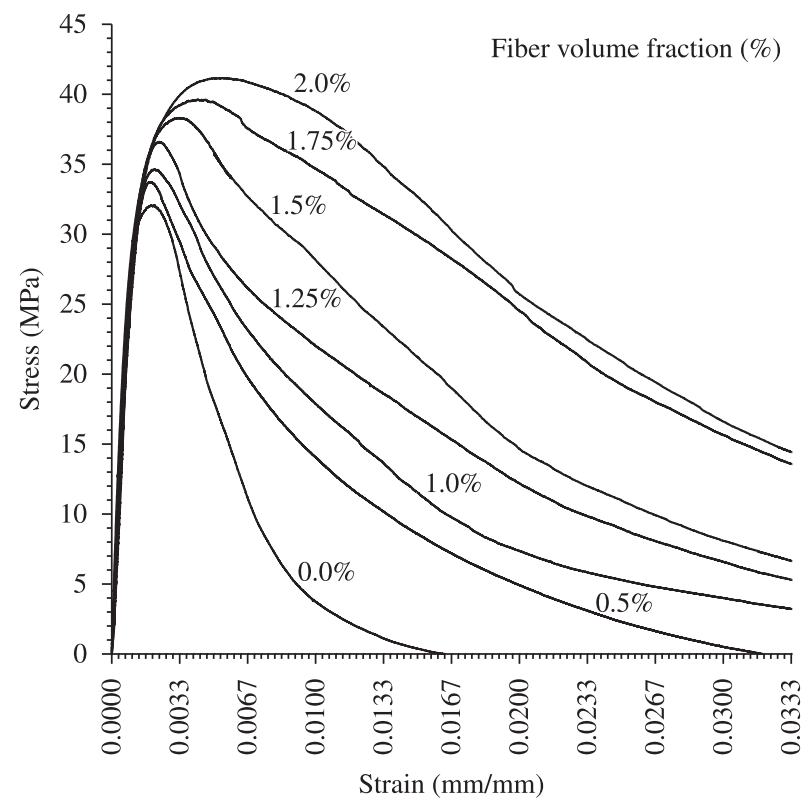

Figure 2. Stress-strain curves of NSSFRC for $1 / \mathrm{d}$ ratio of 75 at fiber volume fraction of $0.0,0.5,1.0,1.25,1.5,1.75$, and $2.0 \%$.

$$
T_{\text {Inf }}=0.03020 V_{f}(l / d)+0.68672
$$

for $0 \leq \mathrm{V}_{\mathrm{f}}(1 / \mathrm{d}) \leq 166$

$$
T_{\text {Ihf }}=0.04378 V_{f}(l / d)+0.87000
$$

for $0 \leq \mathrm{V}_{\mathrm{f}}(\mathrm{l} / \mathrm{d}) \leq 166$

where $T_{I n f}$ and $T_{I h f}$ are compression toughness indices for NSSFRC and HSSFRC, respectively.

Compression specific toughness index $\left(T_{s f}\right)$ balances out differences in compressive strength that is calculated from Equation 6. Compression specific toughness indices for NSSFRC and HSSFRC are given in Table 2. Figure 11 shows the relationship between compression specific toughness index and fiber reinforcement index. As it can be seen from Figure 11, compression specific toughness

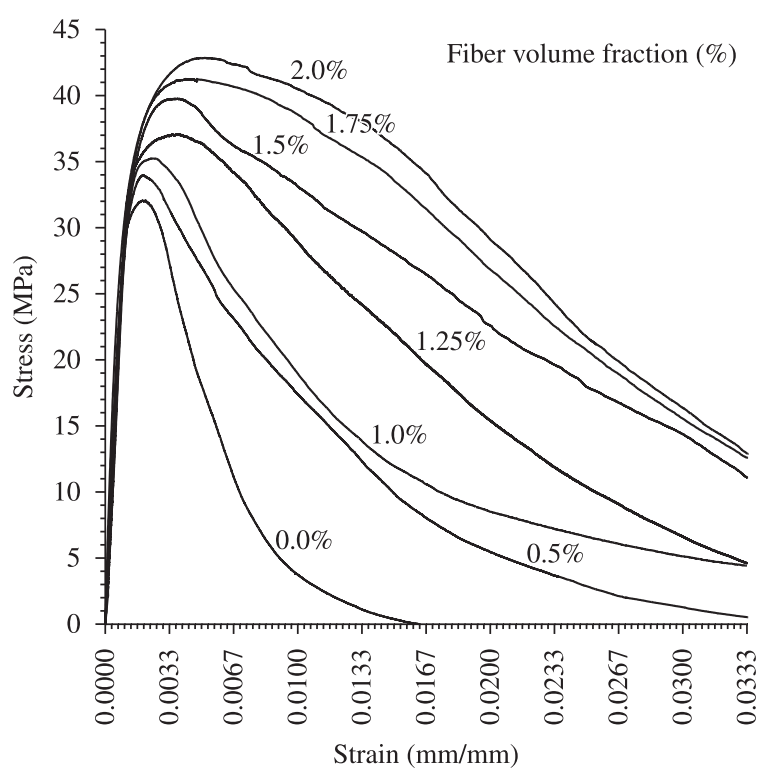

Figure 3. Stress-strain curves of NSSFRC for $1 / \mathrm{d}$ ratio of 83 at fiber volume fraction of $0.0,0.5,1.0,1.25,1.5,1.75$, and $2.0 \%$.

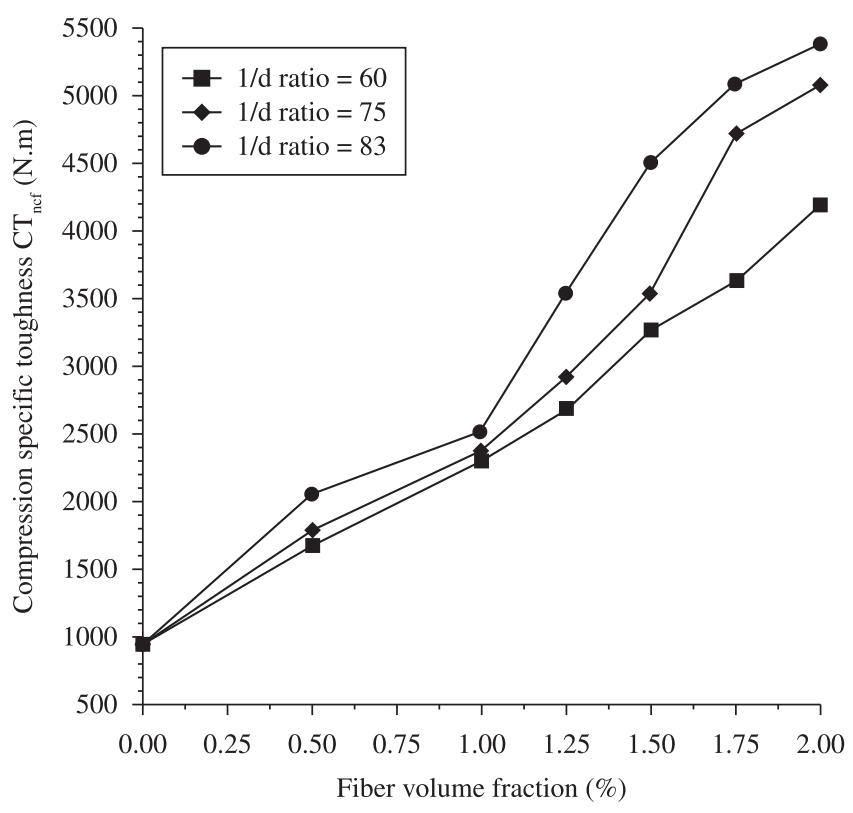

Figure 4. Compression specific toughness of NSSFRC versus fiber volume fraction for $1 / \mathrm{d}$ ratio of 60,75 , and 83 .

index increases with the increase in fiber reinforcement index for both NSSFRC and HSSFRC. Compared to HSSFRC, compression specific toughness index is higher for NSSFRC. Other investigators obtained similar trends ${ }^{14,16}$. From regression analysis, the following linear Equations 7 and 8 were obtained. Equations 7 and 8 quantify the relationship between compression specific toughness index and fiber reinforcement index for NSSFRC and HSSFRC, respectively. $\mathrm{R}_{\mathrm{CMD}}^{2}$ for Equations 7 and 8 is 0.96541 and 0.96534 , respectively.

$$
T_{s f}=\frac{C T_{c f}}{f_{c}^{\prime}}
$$

for $32.06 \leq f^{\prime} \leq 943.56 \mathrm{MPa}$

for $178892.94 \leq \mathrm{CT}_{\mathrm{cf}} \leq 1777341.60 \mathrm{~N} \cdot \mathrm{m} / \mathrm{m}^{3}$ 


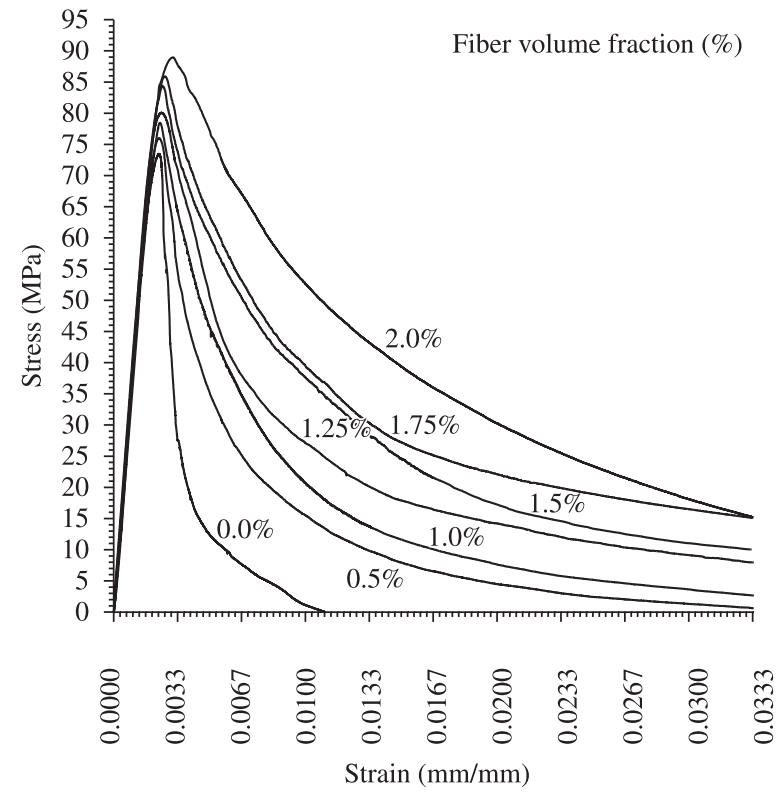

Figure 5. Stress-strain curves of HSSFRC for 1/d ratio of 60 at fiber volume fraction of $0.0,0.5,1.0,1.25,1.5,1.75$, and $2.0 \%$.

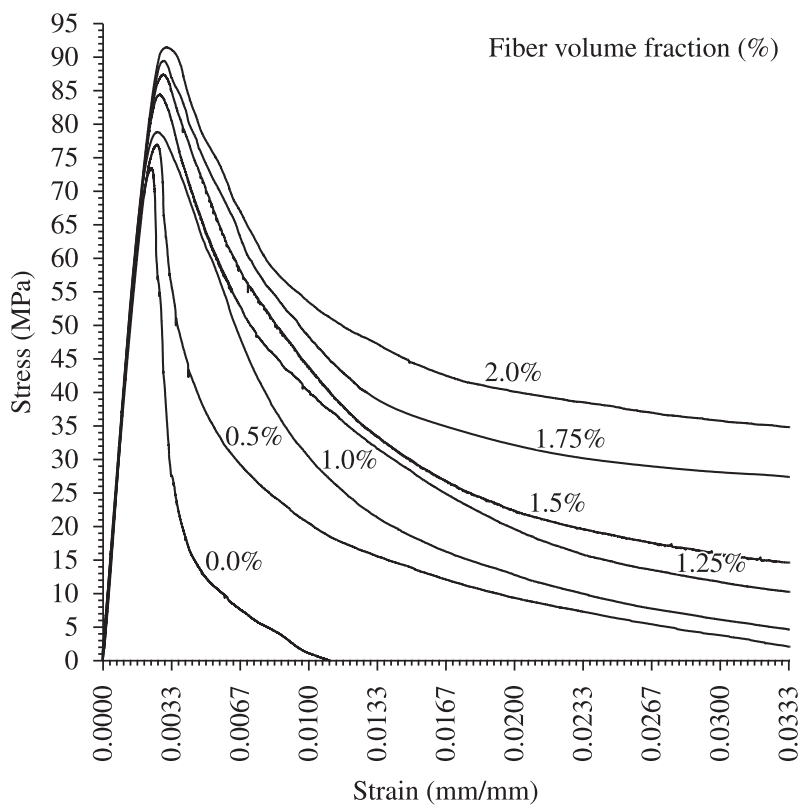

Figure 6. Stress-strain curves of HSSFRC for $1 / \mathrm{d}$ ratio of 75 at fiber volume fraction of $0.0,0.5,1.0,1.25,1.5,1.75$, and $2.0 \%$.

$$
T_{\text {snf }}=T_{s n}+0.11638 V_{f}(l / d)-0.02343
$$

for $0 \leq \mathrm{V}_{\mathrm{f}}(\mathrm{l} / \mathrm{d}) \leq 166$

$$
T_{\text {shf }}=T_{\text {sh }}+0.09262 V_{f}(l / d)+0.67282
$$

for $0 \leq \mathrm{V}_{\mathrm{f}}(\mathrm{l} / \mathrm{d}) \leq 166$

where

$f^{\prime}$ is compressive strength of concrete $(\mathrm{Pa})$

$C T_{c f}$ is compression specific toughness per unit volume of concrete (N.m/m $\left./ \mathrm{m}^{3}\right)$

$T_{s n f}, T_{s h f}, T_{s n}$, and $T_{s h}$ are compression specific toughness indices for NSSFRC, HSSFRC, plain normal strength concrete, and plain HSC, respectively.

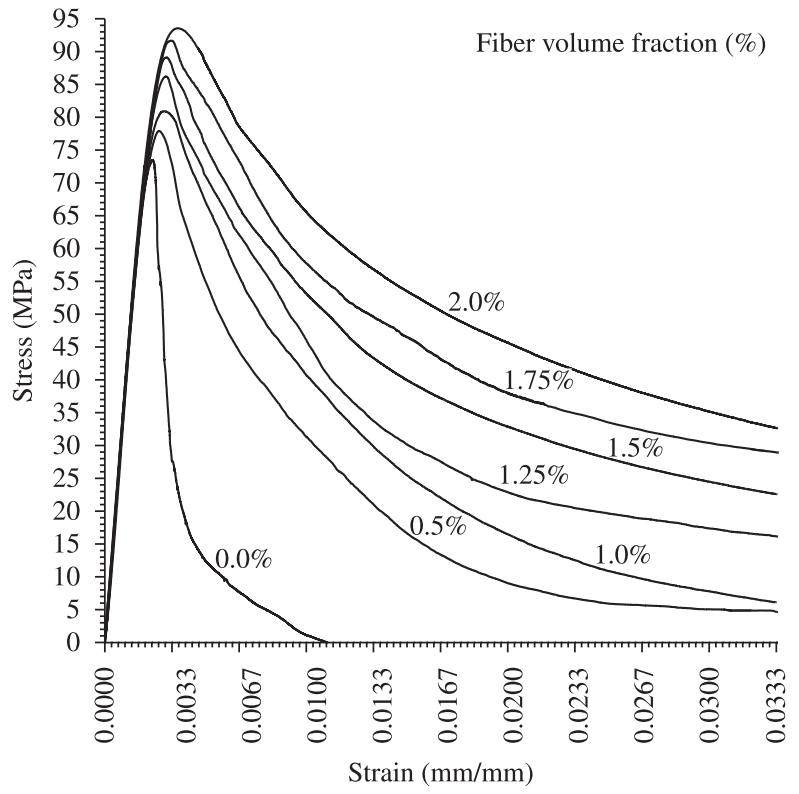

Figure 7. Stress-strain curves of HSSFRC for $1 / \mathrm{d}$ ratio of 83 at fiber volume fraction of $0.0,0.5,1.0,1.25,1.5,1.75$, and $2.0 \%$.

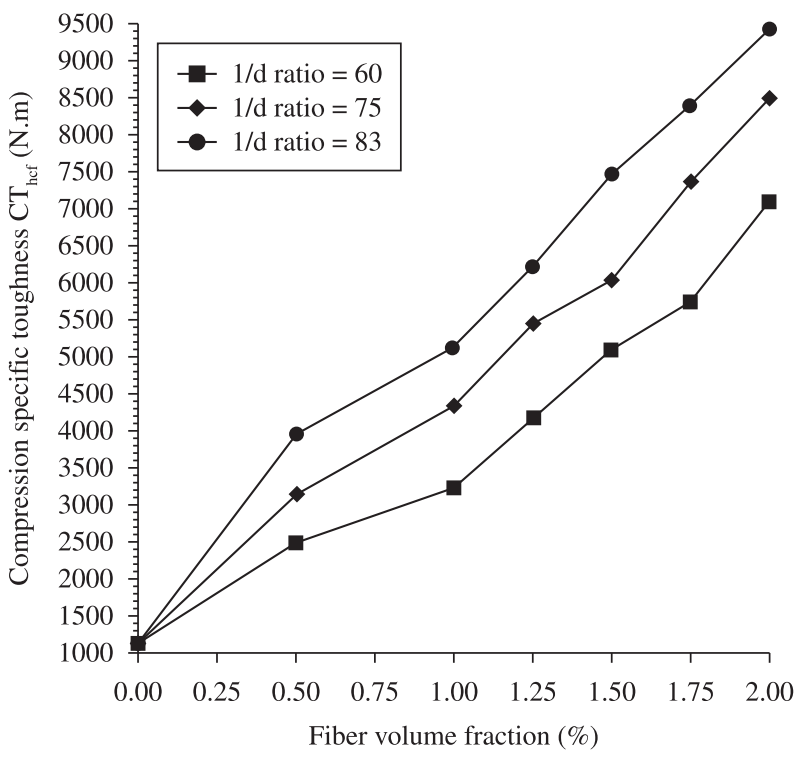

Figure 8. Compression specific toughness of HSSFRC versus fiber volume fraction for $1 / \mathrm{d}$ ratio of 60,75 , and 83 .

\section{Discussion of Results}

Compressive strength test results of NSSFRC and HSSFRC are given in Table 2. As it can be seen from Table 2, as the fiber volume fraction increases and also as FRI increases, compressive strength increases for all NSSFRC and HSSFRC mixes. This increase in compressive strength is due to the fact that, as fiber volume fraction increases the spacing between fibers is reduced, therefore, this allows faster load transfer and support by the adjacent fibers. The maximum increase in compressive strength is $33.7 \%$ obtained by the NSSFRC mix with $1 / \mathrm{d}$ ratio of 83 and at fiber volume fraction of $2.0 \%$ compared to plain normal strength concrete. For NSSFRC mixes with $1 / d$ ratio of 60 and 75 , the maximum increase in compressive strength is 24.3 and $28.2 \%$, respectively, obtained at fiber volume 


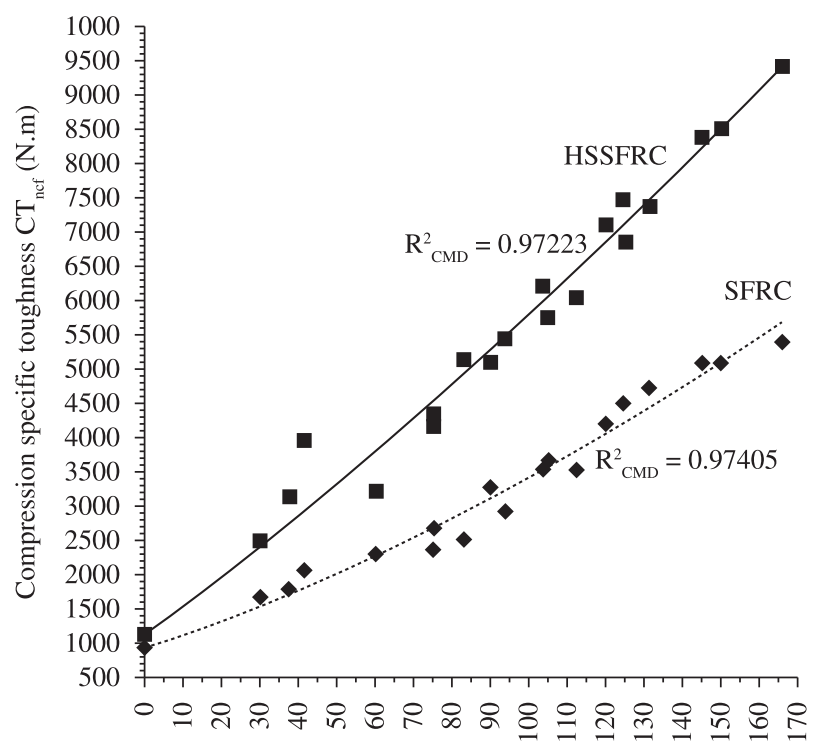

Fiber reinforcement index $\mathrm{V}_{\mathrm{f}}(1 / \mathrm{d})$

$$
\begin{aligned}
& -\mathrm{CT}_{\text {hef }}=\mathrm{CT}_{\mathrm{c}}+41.65914 \mathrm{~V}_{\mathrm{f}}(\mathrm{l} / \mathrm{d})+0.05078\left[\mathrm{~V}_{\mathrm{f}}(\mathrm{l} / \mathrm{d})\right]^{2} \\
& \cdots \cdots \mathrm{CT}_{\text {ncf }}=\mathrm{CT}_{\mathrm{c}}+18.59238 \mathrm{~V}_{\mathrm{f}}(1 / \mathrm{d})+0.06027\left[\mathrm{~V}_{\mathrm{f}}(\mathrm{l} / \mathrm{d})\right]^{2}
\end{aligned}
$$

Figure 9. Relationship between compression specific toughness and FRI for NSSFRC and HSSFRC.

fraction of $2.0 \%$ compared to plain concrete. The maximum increase in compressive strength is $27.30 \%$ obtained by the HSSFRC mix with $1 / \mathrm{d}$ ratio of 83 and fiber volume fraction of $2.0 \%$ compared to plain HSC. For HSSFRC mixes with 1/d ratio of 60 and 75, the maximum increase in compressive strength is 21.05 and $24.50 \%$, respectively, obtained at fiber volume fraction of $2.0 \%$ compared to plain HSC. The increase in compressive strength of fiber reinforced concrete was observed also by other researchers ${ }^{5,24,25}$.

In general, cracking of the concrete begins to take place before reaching the ultimate load as can be observed by the decrease in the slope of the ascending part of the stress-strain curve. Upon reaching the ultimate load, the internal cracks begin to interconnect; therefore, the overall stiffness of the test specimen is reduced. The presence of the steel fibers in the concrete perpendicular to the applied direction of the load can lead to a reduction in the lateral deformations because of their stiffness effect hence the toughness of the steel fiber reinforced concrete is increased. This increase in toughness is influenced by the volume fraction of the steel fibers and on the effectiveness of the steel fibers on bridging the tensile cracks $^{26}$.

It can be seen from Figures 1, 2, and 3 (for NSSFRC) that the area under stress-strain curve increases by the increase in the fiber volume fraction. Figures 1, 2, and 3 obviously show that the post-peak portion of the stress-strain curve is affected by the addition of steel fibers whereas the slope of the ascending branch is not much affected. The descending branch of the stress-strain curve decreases by the increase in the fiber volume fraction. This means that the ductility increases with the addition of steel fibers to plain normal strength concrete.

As can be seen from Figures 5, 6, and 7 (for HSSFRC) the increase in concrete strength reduces its ductility. Plain HSC is a brittle material, and as the concrete strength increases, the descending branch of the stress-strain curve decreases by the increase in the fiber volume fraction. Therefore, the addition of fibers to such concrete

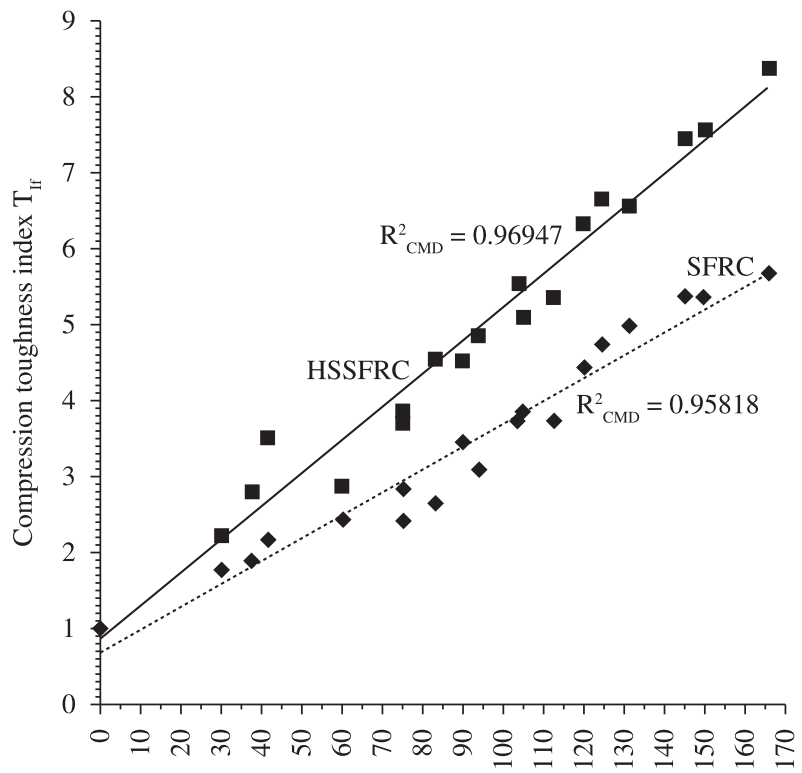

Fiber reinforcement index $\mathrm{V}_{\mathrm{f}}(1 / \mathrm{d})$

$$
\begin{aligned}
& -\mathrm{T}_{\mathrm{Ihf}}=0.87000+0.04378 \mathrm{~V}_{\mathrm{f}}(\mathrm{l} / \mathrm{d}) \\
& \cdots \mathrm{T}_{\mathrm{Inf}}=0.68672+0.03020 \mathrm{~V}_{\mathrm{f}}(\mathrm{l} / \mathrm{d})
\end{aligned}
$$

Figure 10. Relationship between compression toughness index and FRI for NSSFRC and HSSFRC.

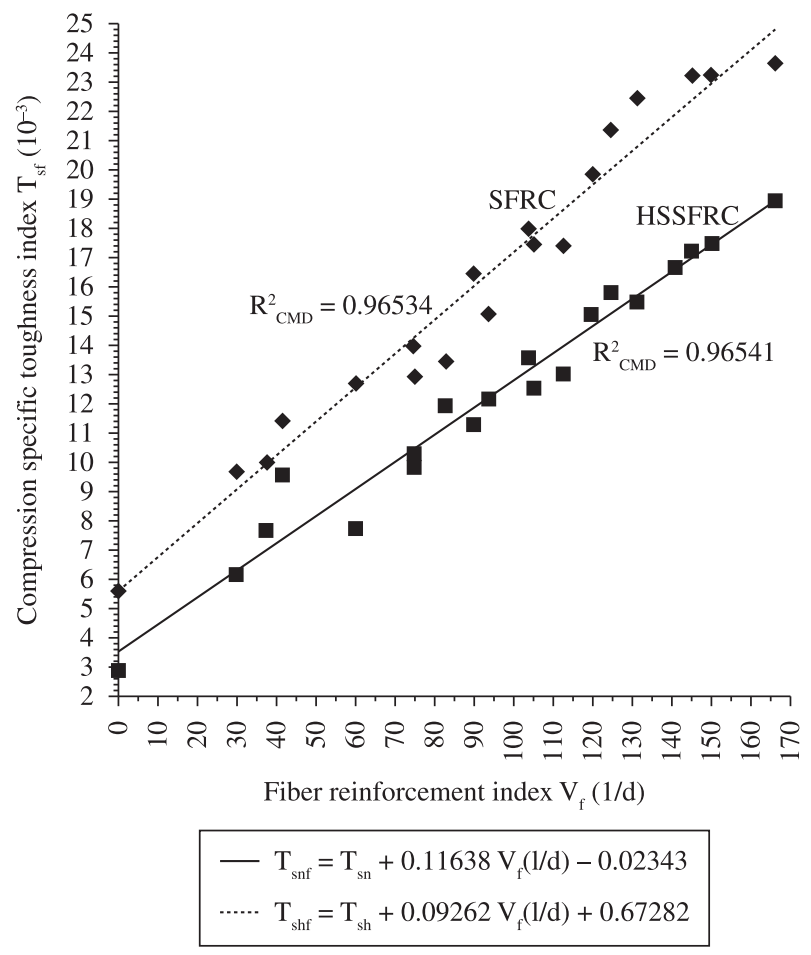

Figure 11. Relationship between compression specific toughness index and FRI for NSSFRC and HSSFRC. 
reduces its brittleness and increases its ductility, as a result it become more homogeneous composite material. When concrete cracks, the randomly oriented fibers arrest the microcracks and limit crack propagation, hence increase in strength and ductility as described by the area under the descending portion of the stress strain curve. In general, strain at peak compressive stress also increase with an increase in fiber volume fraction ${ }^{3}$. It can be seen from Figure 7 that as the fiber volume fraction increases the compression specific toughness increases for all HSSFRC mixes.

From Figure 9 it can be seen that as the FRI increases compression specific toughness increases for both NSSFRC and HSSFRC. The increase in compression specific toughness due to the increase in FRI is indicated by Equations 1 and 2 .

A convenient method to quantify the increase in compression toughness (or ductility in compression) is to use the compression toughness index $\left(T_{I f}\right)$, which can be calculated from Equation 3. It can be observed from Figure 10 that the ductility of NSSFRC and HSSFRC increases as the FRI increases. The increase in $T_{\text {If }}$ for NSSFRC and HSSFRC due to the addition of steel fibers is indicated by Equations 4 and 5, respectively.

\section{Conclusion}

As the fiber volume fraction increases and also as FRI increases, compressive strength increases for all NSSFRC and HSSFRC mixes.

The experimental results indicate that workability of fresh mix NSSFRC and HSSFRC decrease with increase in fiber volume fraction and increase in fiber reinforcement index (FRI). The properties of NSSFRC and HSSFRC in hardened state were generally improved with increase in fiber volume fraction and increase in fiber reinforcement index.

Compression specific toughness is significantly increased with the addition of steel fibers to the normal and high strength concrete. Compression specific toughness of HSSFRC increased for $1 / \mathrm{d}$ ratio of 60,75 , and 83 at fiber volume fraction of $2.0 \%$ by $1.69,1.67$, and 1.75 times that of NSSFRC, respectively.

For 1/d ratio of 60,75 , and 83 at fiber volume fraction of $2.0 \%$, compression specific toughness for NSSFRC were 4.43, 5.36, and 5.68 times higher than that of plain normal strength concrete, respectively. On the other hand, for $1 / \mathrm{d}$ ratio of 60,75 , and 83 at fiber volume fraction of $2.0 \%$, compression specific toughness were 6.33 , 7.56, and 8.38 times higher than that of plain HSC, respectively.

Equations 1 and 2 were obtained and can be used to estimate compression specific toughness of NSSFRC $\left(C T_{n c f}\right)$ and HSSFRC $\left(C T_{h c}\right)$, respectively as a function of FRI and the compression specific toughness of plain concrete $\left(C T_{c}\right)$.

As FRI increased, compression toughness index increased for both NSSFRC and HSSFRC. Compression toughness index can be estimated for NSSFRC and HSSFRC by using Equations 4 and 5, respectively.

Compression specific toughness index increases with increase in FRI for both NSSFRC and HSSFRC. Compression specific toughness index can be estimated for NSSFRC and HSSFRC by using Equations 7 and 8, respectively.

\section{References}

1. American Concrete Institute - ACI. ACI 363R-92. State of the art report on High-Strength Concrete. In: ACI Manual of Concrete Practice (MCP), Part 5. Farmington Hills: American Concrete Institute; 2002.

2. Eren Ö, Marar K and Çelik T. Effects of silica fume and steel fibers on some mechanical properties of high-strength fiber-reinforced concrete. Journal of Testing and Evaluation. 1999; 27(6):380-387.
3. Marar K, Eren Ö and Çelik T. Relationship between impact energy and compressive toughness energy of high-strength fiber-reinforced concrete. Materials Letters. 2001; 47(4-5):297-304. http://dx.doi.org/10.1016/ S0167-577X(00)00253-6

4. Mohammadi Y, Singh SP and Kaushik SK. Properties of Steel Faibrous Concrete Containing Mixed Fibers in Fresh and Hardened State. Construction and Building Materials. 2008; 22(5):956-965. http://dx.doi. org/10.1016/j.conbuildmat.2006.12.004

5. Köksal F, Altun F, Yiğit İ and Şahin Y. Combined Effect of Silica Fume and Steel Fiber on the Mechanical Properties of High Strength Concretes. Construction and Building Materials. 2008; 22(8):1874-1880. http://dx.doi.org/10.1016/j.conbuildmat.2007.04.017

6. Lin W-T, Huang R, Lee C-L and Hsu H-M. Effect of Steel Fiber on the Mechanical Properties of Cement-Based Composites Containing Silica Fume. Journal of Marine Science and Technology. 2008; 16(3):214-221.

7. Xu BW and Shi HS. Correlations Among Mechanical Properties of Steel Fiber Reinforced Concrete. Construction and Building Materials. 2009; 23(12):3468-3474. http://dx.doi.org/10.1016/j.conbuildmat.2009.08.017

8. Soroushian P, Bayasi Z and Khan A. Development of Aramid Fiber Reinforced Cement Composites. In: Daniel JI and Shah SP, editors. ThinSection Fiber Reinforced concrete and Ferrocement. Detroit: American Concrete Institute; 1990. p. 79-98.

9. Wang ZL, Shi ZM and Wang JG. On the Strength and Toughness properties of SFRC Under Static-Dynamic Compression. Composites: Part B. In Press. http://dx.doi.org/10.1016/j-compositesb.2011.01.027

10. Holschemacher K, Mueller T and Ribakov Y. Effect of Steel Fibers on Mechanical Properties of High-Strength Concrete. Materials and Design. 2010; 31(5):2604-2615. http://dx.doi.org/10.1016/j.matdes.2009.11.025

11. Mindess S and Banthia N. Fiber Reinforced Cementitious Composites: Current Practice and Future Prospects. In: Proceedings of V. M. Malhotra Symposium Concrete Technology: Past, Present, and Future; 1994; Berkeley. Detroit: American Concrete Institute; 1994. p. 417-446.

12. Otter DE and Naaman AE. Properties of Steel Fiber Reinforced Concrete Under Cyclic Loading. ACI Materials Journal. 1988; 85(4):254-261.

13. Hsu LS and Hsu C-TT. Stress-Strain Behavior of Steel-Fiber HighStrength Concrete Under Compression. ACI Materials Journal. 1994; 91(4):448-457.

14. Taerwe LR. Influence of Steel Fibers on Strain-Softening of High-Strength Concrete. ACI Materials Journal. 1992; 89(1):54-60.

15. Bayasi Z and Soroushian P. Optimum Use of Pozzolanic Materials in Steel Fiber Reinforced Concrete. Transportation Research Record. 1989; 1226:25-30.

16. Mansur MA, Chin MS and Wee TH. Stress-Strain Relationship of HighStrength Fiber Reinforced Concrete in Compression. ASCE Journal of Materials in Civil Engineering. 1999; 11(1):21-29. http://dx.doi. org/10.1061/(ASCE)0899-1561(1999)11:1(21)

17. Tjiptobroto $P$ and Hansen W. Tensile Strain Hardening and Multiple Cracking in High Performance Cement-Based Composites Containing Discontinuous Fibers. ACI Materials Journal. 1993; 90(1):16-25.

18. Bhargava P, Sharma UK and Kaushik SK. Compressive StressStrain Behavior of Small Scale Steel Fibre Reinforced High Strength Concrete Cylinders. Journal of Advanced Concrete Technology. 2006; 4(1):109-121. http://dx.doi.org/10.3151/jact.4.109

19. American Society of Testing and Materials - ASTM. Annual Book of ASTM Standards, Section 4: Construction, Vol. 04.01, Cement, Lime, Gypsum. Philadelphia: ASTM; 1997.

20. American Society of Testing and Materials - ASTM. Annual Book of ASTM Standards, Section 4: Construction. Vol. 04.02, Concrete and Aggregates. Philadelphia: ASTM; 1994.

21. British Standards Institution - BSI. BS 1881-104: Testing Concrete Part 104: Method for Determination of Vebe Time. London: BSI; 1983.

22. British Standards Institution - BSI. BS 1881-111: Testing Concrete Part 111: Method of Normal Curing of Test Specimens (20 Degrees C Method). London: BSI; 1983. 
23. Choi S, Thienel K-C and Shah SP. Strain Softening of Concrete in Compression Under Defferent End Constraints. Magazine of Concrete Research. 1996; 48(175):103-115. http://dx.doi.org/10.1680/ macr.1996.48.175.103

24. Brandt AM. Fiber Reinforced Cement-Based (FRC) Composites After Over 40 Years of Development in Building and Civil Engineering. Composite Structures. 2008; 86(1-3):3-9. http://dx.doi.org/10.1016/j. compstruct.2008.03.006
25. Atiş CD and Karahan O. Properties of Steel Fiber Reinforced Fly Ash Concrete. Construction and Building Materials. 2009; 23(1):392-399.

26. Hughes BP and Fettuhi NI. Stress-Strain Curves for Fibre Reinforced Concrete in Compression. Cement and Concrete Research. 1977; 7(2):173-184. http://dx.doi.org/10.1016/0008-8846(77)90028-X 